Gomez, S., Ballard, G., Arroyo, P., Hackler, C., Spencley, R., and Tommelein, I.D. 2020. "Lean, Psychological Safety, and Behavior-Based Quality: A Focus on People and Value Delivery." In: Tommelein, I.D. and Daniel, E. (eds.). Proc. $28^{\text {th }}$ Annual Conference of the International Group for Lean Construction (IGLC28), Berkeley, California, USA, doi.org/10.24928/2020/0056, online at iglc.net.

\title{
LEAN, PSYCHOLOGICAL SAFETY, AND BEHAVIOR-BASED QUALITY: A FOCUS ON PEOPLE AND VALUE DELIVERY
}

\author{
Sulyn Gomez ${ }^{1}$, Glenn Ballard ${ }^{2}$, Paz Arroyo ${ }^{3}$, Cory Hackler ${ }^{4}$, \\ Rodney Spencley ${ }^{5}$, and Iris D. Tommelein ${ }^{6}$
}

\begin{abstract}
A number of issues regarding quality, safety, and production persist in the construction industry. These issues arise in the form of rework, accidents, delays, cost overruns, and loss of trust. The way companies have been dealing with these issues is problematic because of an insufficiently broad perspective on interconnected processes and overreliance on buffering as opposed to reducing the negative variation itself. One gap in our knowledge concerns the influence of human factors in the design and success of construction processes. Psychological safety, a construct that can help to bridge this gap, is based on assessments about the risks associated with an action. Lean principles, such as respect for people, can be fostered through people being aware of each other's level of psychological safety. This is shown on site when people speak up without constraints, understand each other's expectations, and come to an agreement about the work, which follows the behavior-based quality (BBQ) approach. The paper highlights theoretical conceptions to describe how underlying ideas about Lean, psychological safety, and BBQ are connected in a people-centered approach to improve value delivery. The exploratory research presented in this paper provides empirical evidence to illustrate the linkage of these ideas in practice.
\end{abstract}

\section{KEYWORDS}

Lean construction, psychological safety, behavior-based quality (BBQ), value delivery.

\section{INTRODUCTION}

Researchers have studied different approaches that construction companies adopted for moving towards increasing value delivery, such as collaborative decision-making (Arroyo and Long 2018), teamwork (Mitropoulos and Memarian 2012), and shared risk

1 PhD Candidate, Civil and Environmental Engineering Department, University of California, Berkeley, CA 94720-1712, USA, sulyn@berkeley.edu, orcid.org/0000-0003-2367-9880

2 Research Associate, Project Production Systems Laboratory, University of California, Berkeley, CA 94720-1712, USA, gballard@berkeley.edu, orcid.org/ 0000-0002-0948-8861

3 Quality Leader, DPR Construction, San Francisco, CA 94111, USA, paza@dpr.com, orcid.org/00000002-8098-8172

$4 \quad$ Lean Leader, DPR Construction, Redwood City, CA 94063, USA, coryha@dpr.com, orcid.org/00000002-1103-5968

5 Director for Quality, DPR Construction, Redwood City, CA 94063, USA, rodneys@dpr.com, orcid.org/0000-0003-2263-543X

6 Prof., Civil and Envir. Engrg. Dept., Director, Project Production Systems Lab., Univ. of California, Berkeley, CA 94720-1712, USA, tommelein@berkeley.edu, orcid.org/0000-0002-9941-6596 
and reward (Ballard et al. 2015). Construction has been described as one of the most dynamic, risky, uncertain, and challenging industries (Mills 2001). Edmondson (2018) proposed that psychological safety is vital for industries with high levels of uncertainty and interdependence. Schein (1985) said that the essence of psychological safety is that "we can imagine [and potentially express] a needed change without feeling a loss of integrity or identity." He described that it is a state where people feel their "self" is not threatened (i.e., their identity, integrity, or membership in groups they care about will not be damaged). Kahn (1990 p. 708) broadens the concept beyond organizational change and defined psychological safety as "feeling able to show and employ one's self without fear of negative consequences to self-image, status, or career," meaning that individuals are comfortable being themselves and they are not afraid to admit an error because they expect to receive help, not harm from confessing. Edmondson (1999 p. 350) extended the concept to teams and defined psychological safety as "a shared belief that the team is safe for interpersonal risk-taking," meaning that individuals will mutually respect each other and not get embarrassed, rejected, or punished for speaking up.

A construction project can be seen as a social unit that brings together people from different backgrounds, beliefs, and perceptions to deliver a project. Psychologists and sociologists highlighted that people's beliefs and actions are shaped to some extent by the beliefs and actions of others in the same group (Dweck 2006). To increase the likelihood of successfully delivering a project, it is important to understand the project team dynamics (how team members measurably interact together as a team). In construction, history has taught people that making a mistake or not knowing something can have negative consequences for the person making the mistake (Juran 1995). Such lessons have caused workers' inhibition and unwillingness to speak up to avoid risks. This influences the reliability of people's commitments in many ways. For example, they might agree to do something just because they cannot say "no" to a request or because they opt to commit to something when they are not confident of being able to achieve it. Research provides evidence that people work in environments where they often do not feel safe to speak up (Milliken et al. 2003). This can impact the trust and ability of people to discuss the scope of a deliverable, define expectations around multiple project participants, and commit to a well-defined scope of work, steps that have been described as being part of a process to manage quality, called behavior-based quality (BBQ) (Spencley et al. 2018).

Edmondson (2012) said that in most organizations, the value generated for customers is delivered by teams. Edmondson and Reynolds (2016) described how with globalization, speed of change, fast schedules, and variety of expertise required for most tasks, more people have to collaborate with others in their work. Schein (1992) said that psychological safety can help to overcome defensiveness and learning anxiety in an era where managing the change is not enough but managing surprises faster and faster is the new priority. Spencley et al. (2018) and Gomez et al. (2019) proposed that a BBQ approach will increase the likelihood of managing surprises in construction projects and achieving the expected quality. According to them, BBQ shifts the reactionary approach of quality approaches that act once problems have occurred, and highlights the impact that upstream behaviors have on the outcomes achieved. BBQ is a process where participants understand the scope of work, get alignment and set measurable acceptance criteria on what the work looks like, and then execute it as per the agreed decisions (Spencley et al. 2018). This approach is sound and logical, but without understanding the link with previous studies and concepts already developed, it might not be fully utilized, and it would fail to gain traction like many other quality approaches have (Koskela et al. 2019). 


\section{RESEARCH DESIGN}

The authors explored theoretical foundations to establish the linkage between Lean and the concepts of psychological safety and BBQ. In this paper, they use excerpts of data collected on two construction projects to illustrate the findings from theory. Instruments for data collection included a survey on psychological safety and an in-depth interview about BBQ implementation.

The interview and survey were conducted by the first author with 9 and 169 project participants, respectively. She used a purposive sampling technique for the interview because the intent was to gather the perspective of participants from different companies (e.g., client, subcontractor, general contractor). For the survey, she invited all participants on site, and participation was voluntary. She handed out a physical survey to small groups (1-3 people). Participants in different roles (e.g., journeyman, project engineer, apprentices) completed and returned the survey.

\section{THEORETICAL IMPLICATIONS}

\section{LEAN AND QUALITY}

Juran retraced events in the history of quality and examined trends and directions to offer a prognosis of what will emerge during the twenty-first century (Juran 1995). The focus on quality has shifted from conformance to requirements only (Crosby 1979), to uniformity (Deming 1982), fitness for use (Juran and Gryna 1988), freedom from deficiencies (Juran and Godfrey 1999), and finally to a focus on satisfying customer's conditions of satisfaction (Ballard and Tommelein 2014; Spencley et al. 2018; LCI 2020). The definition of quality has shifted towards delivering projects and achieve client's expectations. Moreover, Crosby (1979 p. 6) suggested that "quality is the all-important catalyst that makes the difference between success and failure."

The Lean pursuit to create value for customers requires understanding the customer's expectations. In addition, tight linkages between Lean and quality are found in the literature. For example, Juran provides suggestions that are consistent with Lean principles such as "respect for people," by suggesting to "answer suggestions from workers promptly and in a manner that shows respect for the worker," and to "treat all people with dignity" (Gryna et al. 2005 p. 127). Similarly, the Lean principle "respect for people" resonates with Deming's principle (1986) "eliminate fear from the workplace," which requires much more than just telling craft workers or engineers that there is no reason to fear and that they can express their doubts, concerns or inquiries about the work. This requirement resonates with what has been discussed in previous sections about psychological safety.

Researchers have highlighted several issues related to quality management including failing to manage subjectivity (Juran 1995; Crosby 1979 p. 27), failing to meet customer needs and relegating responsibility to others (Arditi and Gunaydin 1997), failing to focus on prevention (Crosby 1979 p. 4), etc. Pounds et al. (2015) suggested that companies fail in managing quality because they lack a "systematic approach for addressing the role people play in hindering or improving quality." Most quality approaches focus on drafting policies and regulations, posting slogans, etc., while leaving the responsibility for achieving quality to the quality engineer, quality champion, inspectors, etc. (Flynn 2001). One of the earliest milestones of the quality movement in the United States was Frederick Taylor's publication "Principles of Scientific Management." He suggested separating 
planning from execution; engineers would do the planning while shop supervisors and the workforce would just carry out the plans (Goetsch and Davis 2014). Such an approach had negative consequences on human relations and negative effects on quality because of its premise, which says that the workforce lacked the "literacy" needed to plan the work (Juran 1995). When quality problems arise, options are learning the art of making excuses, or learning the art of prevention (Crosby 1979). People who choose the first option get used to working in an environment with conflict where yelling and screaming are part of the routine. Those who choose the second option will observe the expectation that people do things right because it is the right thing to do. Quality is an important concept when it comes to project performance because understanding and managing it correctly allows errors or defects to be mitigated or prevented from happening in the first place. In construction, all too often we deal with a post-mortem analysis full of surprises because quality issues throughout the construction process went underreported.

\section{Respect for People, a Core Lean Principle for Value Delivery}

In construction, as in many other industries, most of the manpower is represented by craft workers. Crosby (1979) highlighted that quality is directly related to the people executing the operation, but he also said that workers can contribute only a little to prevention because all the planning and creation is done elsewhere (by project staff in the case of construction projects). Respect for people requires that each person be helped to develop their capabilities, and this principle supports the organizational objective of learning and continuous improvement. As people advance their understanding of quality, part of the process includes the "recognition that you cannot, and should not, fool the people" (Crosby 1979 p. 55).

Edmondson (2018) described that in the factory model of management, "underlying the notion of a simple, controllable production system was the notion of the simple, controllable employee." She described how supervisors in this context would use a system of rewards and punishments to motivate employees, creating in this way an unfortunate legacy of fear. Studies in behavioral science have demonstrated that fear inhibits learning and cooperation because fear impairs analytical thinking, creative insight, and problem-solving capabilities (Fox and Shonkoff 2011). Howell et al. (2017) linked the concept of psychological safety with the Lean principle of respect for people, and Edmondson (2018) reinforced this idea by suggesting that respect can thrive in psychologically safe work environments. The principle of respect for people and quality combined fight against the stereotype some have about workers being predictable.

According to Edmondson (2018), today's organizations exist in a knowledgeintensive world, in which success and performance are driven by factors that cannot be measured or overseen such as intelligent experimentation, interpersonal skills, etc. The world she described needs people who are able to share concerns, mistakes, and halfformed ideas without fear of embarrassment or retribution, to speak up with confidence that they won't be humiliated, ignored, or blamed, and to ask questions when they are unsure about something. Edmondson (2018) said that when employees get the message that speed, efficiency, and results are all that matter, they become hesitant about offering ideas, expressing their concerns, or even asking questions because of the preconceived idea of managers expecting to hear the most certain and positive outputs. In a work environment where respect for others govern people's behaviors, individuals have the confidence to talk about mistakes preventing their reoccurrence, to innovate and try new ways to make things better, and to show vulnerability and get clarity on their work. 


\section{Language Action Perspective (LAP)'s Role in Achieving Quality}

Macomber and Howell (2003) connected the Language Action Perspective (LAP) with Lean. They argued that LAP describes the very human processes, the purposeful ways people communicate, by which projects are conceived and delivered. Crosby (1979) said that everything regarding quality must be a result (of planning), not a reaction (as happens with quality control), and planning for customer satisfaction is now a core goal for most companies. As companies strive for client satisfaction and no surprises in quality, project teams are expected to collaborate and behave in ways that allow them to achieve this (e.g., understand the scope of work, design operations). Macomber and Howell point out the study of speech acts and the commitment workflow described by Flores (1982). Clarity of requests and commitments are key in the planning process. A speech act often used in planning projects are "promises," because of the interdependency between tasks and the variety of participants who build a project. Ballard and Tommelein (2016) explained that an essential prerequisite for reliable promises is that suppliers can say "no" to a request. Reasons for saying no are tied to task appropriateness (sequence), readiness to be performed (task definition, soundness, or size relative to capacity), expertise, or constraints. Saying "no" is not easy, especially for those at the bottom of a hierarchy.

Juran (1995) emphasized customer needs as a top priority. However, a customer in construction is no longer an individual only, but a cast of stakeholders who participate in the supply chain. LCI's (2020) definition of quality points to conforming to "customer's valid and agreed-upon conditions of satisfaction." This definition leverages the understanding of quality by inserting some of the work on LAP by adding "conditions of satisfaction" into its definition. Winograd (1986) said that "conditions of satisfaction are not objective realities, independent of interpretations. They exist in the listening, and there is always the potential for difference among the parties." Following this statement, requirements that are seen as a defined and already pre-assembled set of instructions might not fit under the definition of "valid and agreed-upon conditions of satisfaction." This is because their definition may not stem from a conversation where expectations are articulated and shared understanding is achieved, and because it neglects the possibility of the customer changing their expectations as the project is built.

\section{Psychological SAFETY AND QUALITY}

Deming (1986 p. 26) said, "top management should publish a resolution that no one will lose their job for contribution to quality and productivity." History, though, has evolved cultures where fear is engrained in the work. Juran (1995 p. 614) used The Code of Hammurabi as an example (ca. $2000 \mathrm{BC}$ ), which prescribed the "death penalty" for any builder of a house that collapsed and killed the owner. Such conflicting environments where errors could carry fatal consequences have created an environment where fear governs, and decisions are constrained due to the consequences that may result from such decisions. Edmondson (2018) suggested that people might choose not to speak up, even though consequences can harm the team, in exchange for self-protection. This can cause unhelpful or unhealthy behaviors, having as a result people who "hold back on everything from good ideas to great questions." Construction projects require integrating knowledge from diverse areas of expertise; in such an environment, psychological safety is a requirement for success. Psychological safety, because of its positive association with learning behaviors, can facilitate achieving the goal of avoiding surprises by working upstream in uncovering and aligning expectations, setting up clear objectives and criteria to measure success in achieving quality. 
Edmondson (2018) highlighted that even though many methods of surfacing failures exist, they are underutilized as people remain reluctant to convey bad news (e.g., anything that did not go as planned). She said that a knowledge-intensive world requires valuable forms of speaking up, such as: (1) asking questions when they are unsure about something, (2) sharing concerns, mistakes, and half-formed ideas without fear of embarrassment, (3) speaking up with confidence that they won't be humiliated, ignored, or blamed, (4) raising a different point of view, (5) asking a colleague for feedback and providing constructive feedback, (6) admitting that a project is over budget or behind schedule, (7) communicating challenges, concerns, and opportunities, and (8) reporting errors and appreciating employee's observations, questions, concerns. Such speaking up can greatly influence achieving the expected outcome of quality.

\section{Psychological Safety for Pursuing Improvement and Building Learning Behaviors}

Edmondson (2012) highlighted that humans, as social creatures, have pleasure when we create, share, or implement new ideas. Edmondson (2018) highlighted that dozens of studies today have proven that psychological safety opens opportunities for greater learning behaviors, performance improvement, and even lower mortality. A main concern regarding quality is people not reporting errors when discovered.

Many studies have captured causes for workplace silence. Milliken et al. (2003), for example, found that employees remained silent mostly because of self-image as they did not want to be viewed or labeled negatively nor damaged valued relationships. Construction is an industry where trades are hierarchically organized. If people feel that their saying could be interpreted as negative or threatening to their superiors, they will likely keep silent (Ryan and Oestreich 1991) or behave in a self-protective manner (Athanassiades 1973). For example, workarounds were highlighted by Tucker and Edmondson (2003) as a way to immediately solve a problem. It enables people to do their job, but in doing so, new problems are created. The workaround is not a long-term solution. When no diagnosis for the first problem is performed, problems are likely to recur. Research has linked psychological safety with speaking up and error reporting (Frese and Keith 2015). Psychological safety can set the path for long term solutions.

\section{Psychological Safety in Understanding Requirements: Behavior-Based Quality}

Juran (1995) highlighted that while the twentieth century was the center of productivity, the twenty-first century would be known as the century of quality. The new century in construction is characterized by complex designs requiring precise execution and the need to prevent defects and failures from happening in the first place. Crosby (1979) realized that the "conventional approach [to quality] was not effective" but "some beliefs are so ingrained that they cannot be changed just by suggesting they are wrong." He developed concepts for how he understood quality management being focused on prevention and described its implementation as people-oriented. Pounds et al. (2015) highlighted the impact of human behavior is achieving quality, saying that "quality is a result of what frontline employees do or don't do." The role frontline employees play is key in the process of quality; however, the authors of this paper also highlight the role of "first planners" in this process (Gomez et al. 2019). In building psychological safety, it is expected that every member of the team takes ownership of their contribution to the process to achieve quality.

Deming (1982 p. 5) said that "quality begins with the intent" and, in construction, intent gets translated into a set of documents (i.e., drawings, specifications, contract). 
However, the intent can change over time or be subject to interpretation. Dougherty (1992) highlighted that people from different disciplines have specialized training and use specific terminology for the field in which they work and when different disciplines are put together, as in the case on construction projects, teams have to be careful with what is taken for granted by people in different disciplines. Tasks in construction combine multiple disciplines and require judgment, coping with uncertainty, implementing new ideas, coordinating, and communicating with others. If project teams are not able to move things from unknown to known, every day will likely have its surprises. While some quality approaches send the message of "don't blame the people, fix the process," the behavioral approach to quality says, "fix the process and develop the behaviors expected" (Pounds et al. 2015). If certain behaviors are built to prevent surprises, people will be able to create processes that can be repeated and delivered at any scale.

In the Lean world, reliable promising can be understood as the basic process underlying BBQ, a quality approach focusses on people's behaviors. Also, the underlying behaviors for BBQ can be understood as those enabled by psychological safety; namely, to speak truth to power, to feel free to ask questions and make suggestions and ask for help, and to be confident that mistakes you make will be met not with punishment but with help. While reliable promising has been recognized as a critical element in planning and coordination, its application is much broader and includes situations in which one or more people are responsible for delivering or providing something to someone else. Such deliverables might be provided by a team to others whom they might not work directly with; e.g. producing and sending drawings (architects or designers activities) to clash detection teams (from the general contractor or subcontractors) or producing and sending invoices for payment. Clarification and alignment of customer and provider is the first step in reliable promising, and commitments are made only if there is a thoughtful consideration of the capability to deliver on that commitment. Clients deserve to know exactly what companies have committed to deliver and must receive exactly that.

\section{IMPLICATIONS IN PRACTICE AND DISCUSSION}

\section{ResPeCt For People ANd Its IMPACt ON Processes}

Respect for people has a vast influence on designing construction processes and operations. Including team members in meetings and understanding expectations to plan the work are examples of what this can look like in the field. Participant testimonies from the first author's site interviews described respect for others in different ways:

- "bringing in craftspeople allowed us to incorporate their constructability suggestions. In some cases, they suggest solutions that exceeded what we thought they could do ... [e.g.,] we just met with the terrazzo subcontractor and he made suggestions that will result in a better job and in a better installation than we had anticipated."

- "there is an ethos that we are all part of one big team, and I think everybody being on site tends to create that sense of camaraderie and sense of common goals."

- ' 'in terms of being able to predict the outcome we've been doing really well and having the subcontractors here in the big room is enabling that quite well."

- "it is important that the expectations of quality are conveyed to the subcontractors and the people who are actually doing the work in the field." 
Psychological safety fosters respect for others and builds environments of mutual, measurable, authentic care where interpersonal risk-taking is welcome. When people feel psychologically safe and respected, they speak up freely and are not constrained by others' disapproval or negative responses. People feeling psychologically safe facilitates active and open participation in process design and ownership of operations. For instance, participants in a meeting to define quality expectations would be more likely to speak up and therefore add value with their expertise on a subject. Similarly, tasks such as sweeping will be equally valued and respected as tasks that produce progress such as placing concrete because they impact the quality of the work and everyone's safety.

\section{UNDERSTANDING VALUE BEYOND REQUIREMENTS}

Quality approaches that focus on satisfying requirements fail in recognizing (1) the ability of stakeholder's leadership to facilitate a process that supports psychological safety and (2)that plans and specs might not be totally accurate, complete, or might not clearly express client expectations. Interviewees in the study highlighted this issue:

- "program documents did not necessarily reflect everybody's goals and demands and technical requirements, and of course those might have changed over time."

- "sometimes we [client/client's representative] do not communicate well our priorities to the people building the projects."

- "that's only like 3 words in the specs [referring to bench welding details], but that's the very first thing they went to [architects when reviewing the mock-up]."

- "there are certain things that might not be as clear in the drawings and that you explicitly write down during those [quality expectations] meetings."

Work in construction needs to be coordinated with multiple people across boundaries of expertise, distance, companies, etc. No two construction projects are alike, everyone in the team has to get up to speed quickly and transform drawings and specifications into buildings. Not all teams in a construction project are the same either. Understanding expectations about what quality means is necessary to deliver value in the project. Specifying quality requires an understanding of project participants' expectations, which sometimes are not completely contained in the project documents. People must feel psychologically safe to speak their minds and express their expectations and concerns. It is expected that the process of understanding what stakeholders value occurs in project programming. However, the client's expectations can change as the project gets executed, which makes it necessary to follow a process to define and update what quality means for that specific scope of work. Psychological safety allows participants to express what is needed to reach a common understanding of expectations and achieving the client's objectives. Examples of participant efforts for delivering value in the project are:

- "Architect $\mathrm{ABC}$ was engaging in coordination sessions with about 35 different user groups from Client A to make sure that the building program, as well as the realization of the documents, reflected what Client A intended as well."

- "I think the [quality] meetings are essential in making sure that each has communicated their quality intent and that the objective of the work is reflected in the people who are going to actually realize it.

- "it [BBQ] implies that all project participants are focused on achieving [measurable] results for themselves and the client, based on the known and unknown factors of the project." 
- "That was the first step in the quality process, embracing the intent and understanding the intent of the design and then coordinating our efforts."

Research participants realized that the BBQ process gave them some level of transparency that allowed them to build what the client really wanted, something that has been challenging to achieve with traditional quality approaches in construction. Using BBQ allowed the construction team to identify gaps in the design (drawings and specifications). BBQ also helped clients and architects in the project to take a more informed decision based on constructability, schedule, and cost early in the process.

\section{Influencing Psychological Safety in Construction Projects}

Psychological safety can shape project participants' interaction and make the difference between identifying expectations early on in a project and postponing the discovery of underlying problems and potential defects. Value delivery in construction projects can include creating a psychologically safe work environment. Project participants from different backgrounds get together and collaborate within and among teams in a fast and changing environment. In this scenario, it is important to assure that people are paying attention, hearing each other, sharing information, and having a common understanding of the work to be executed. To foster an environment where this can occur, the authors identified factors that contribute to increasing psychological safety in construction projects. In the questionnaire to measure psychological safety, the authors posed the openended question: "What would help you feel safe to raise concerns, make suggestions, ask questions, and feel confident that if you make a mistake, you will get help, not punishment?" This elicited responses that we categorized into 11 factors (Table 1).

Table 1: Factors that Contribute to Increasing Psychological Safety in Construction

\begin{tabular}{cc}
\hline Factors Contributing to People Speak Up & Number of responses (108) \\
\hline Strength relationship with supervisor & 20 \\
Safety meetings, talks, and training & 17 \\
Anonymous suggestion & 13 \\
Assurance that punishment is not a result of speaking up & 12 \\
Strength relationship within and among trades & 12 \\
My voice is heard, and actions are taken & 9 \\
Recognition & 9 \\
Prevention and caring common areas & 7 \\
Opportunity to participate in planning work activities & 5 \\
Time to raise concerns and a person of contact to report to & 2 \\
Staff involvement in the field & 2 \\
\hline
\end{tabular}

Hierarchy and status differences can make it difficult for some employees to speak up and express their concerns. Working on strengthening the relations with their supervisors was identified among the top contributing factors for psychological safety. This factor includes the communication between craft and supervisors and how supervisors would behave or react in certain circumstances. Frontline employees are sensitive to what their supervisors say and do. For example, if supervisors are not attentive, frontline employees might feel unimportant and that their work is not valued. In construction, superintendents 
play an important role because craft workers look up to them. Supervisors can demonstrate the behaviors they expect to see on their teams and convince them that their feedback is needed to do a better job, more safely.

Other important contributing factors included the assurance that workers would not be punished for speaking up when they report mistakes, errors, or ask questions, and strengthening relationships within and among trades. When people face the potential for threat or embarrassment, their learning is inhibited. By increasing the level of familiarity among team members interpersonal threats may be lowered and people may be encouraged to ask for help, admit errors, and discuss problems.

\section{CONCLUSIONS}

Lean, psychological safety, and behavior-based quality (BBQ) are related in their pursuit and means to deliver greater value. Lean is a philosophy often described as having the customer as the number one priority. However, construction, as a multidisciplinary industry, is highly dependable on the performance of each of its players. Therefore, it is important to account for all project participants (internal and external customers) because of the role they play in achieving the success of the project. If all players involved are not aligned, we expect to see fractures in psychological safety and therefore failures in quality. People's behaviors are influenced by how they feel in a certain environment. In defining quality for any scope of work, having an environment where psychological safety governs would help project participants rely on each other to speak up in case they miss a detail, are distracted, or do not have their priorities aligned with the priorities of the project. Due to the nature of construction projects based on teams, many issues can be overcome through understanding and caring about psychological safety. People's behaviors can be shifted towards pursuing learning and improvement in all the areas, increasing the likelihood that quality expectations will be met, and safety will be a priority for all. Individuals and teams can acquire the habit of learning as something they do naturally. Asking "How do we make sure we achieve client expectations? What can we learn? and What can we do better?" can become habitual, the first impulse when faced with responsibility for deliverables, requests, errors, injuries, and promises that should have been kept.

Lean, psychological safety, and quality all lead to or require respect for the individuals. With "respect for people," you see an increase in productivity, higher quality, and more open conversations and communication. We see many projects struggling to make this connection, and the outcome is that everyone suffers. The owner suffers from a lack of trust leading to frustration. The design team feels like they are on their own trying to fit the owner's requests into constructible buildings. The contractors struggle from a paralyzed management group that cannot decide fast enough to keep quality and production moving forward. What if we focused on building a team first, then building a building second? If teams apply Lean, opening a work environment of psychological safety, then the outcome would be a higher likelihood of achieving expected outcomes. The industry would have owners trusting their teams to come up with solutions. It would have designers teaming up with builders to work out the best means to build a quality product the first time. It would have builders facilitating answers to issues that stop work in the field, engaging crafts in collaboration in the process simply because it is the right thing to do. Psychological safety would open the way to change the future of construction. 


\section{ACKNOWLEDGMENTS}

Development of the ideas presented in this paper was supported in part by gifts made to the Project Production Systems Laboratory (P2SL). Any opinions, findings, conclusions, or recommendations expressed in this paper are those of the authors and do not necessarily reflect those of contributors to P2SL.

\section{REFERENCES}

Arditi, D. and Gunaydin, H.M. (1997). "Total Quality Management in the Construction Process." International J. of Project Management, 15(4), 235-243.

Arroyo, P. and Long, D. (2018). "Collaborative Design Decisions." Proc. $26^{\text {th }}$ Ann. Conf. Int. Group for Lean Constr., Chennai, India, 18-20 July, pp. 463-472.

Athanassiades, J.C. (1973). "The Distortion of Upward Communication in Hierarchical Organizations." Academy of Management Journal, 16(2), 207-226.

Ballard, G., Dilsworth, B., Do, D., Low, W., Mobley, J., Phillips, P., Reed, D., Sargent, Z., Tillmann, P., and Wood, N. (2015). "How to Make Shared Risk and Reward Sustainable." Proc. 23 ${ }^{\text {rd }}$ Ann. Conf. Int. Group for Lean Constr., Perth, Australia, 2931 July, pp. 257-266.

Ballard, G. and Tommelein, I. (2014). Built-in Quality Cycle. Project Prod. Systems Lab. (P2SL), White Paper 1, http://p2sl.berkeley.edu/white-papers/ visited 25 May 2020.

Ballard, G. and Tommelein, I. (2016). Current Process Benchmark for the Last Planner ${ }^{\circledR}$ System. https://goo.gl/rS42Wa visited 25 May 2020.

Crosby, P.B. (1979). Quality is Free: The Art of Making Quality Certain. McGraw-Hill (NY), New York, Vol. 94.

Deming, W.E. (1982). Quality, Productivity and Competitive Position. MIT, Cambridge, MA, US, pp. 229-373

Deming, W.E. (1986). Out of the Crisis. MIT Press., Cambridge, MA, US, pp. 524.

Dougherty, D. (1992). "Interpretive Barriers to Successful Product Innovation in Large Firms." Organization Science, 3(2), 179-202.

Dweck, C. (2006). Mindset: The New Psychology of Success. Random House Digital, Inc.

Edmondson, A.C. (1999). "Psychological Safety and Learning Behavior in Work Teams." Administrative Science Quarterly, 44(2), 350-383.

Edmondson, A.C. (2012). Teaming: How Organizations Learn, Innovate, and Compete in the Knowledge Economy. John Wiley \& Sons.

Edmondson, A.C. (2018). The Fearless Organization: Creating Psychological Safety in the Workplace for Learning, Innovation, and Growth. John Wiley \& Sons.

Edmondson, A.C. and Reynolds, S.S. (2016). Building the Future: Big Teaming for Audacious Innovation. Berrett-Koehler Publishers.

Flynn, K. (2001). "Behavior-Based Quality - Connecting People to the Systems." Proc. Behavioral Science Technology Annual Spring Conf., Chicago, IL.

Flores, F. (1982). Management and Communication in the Office of the Future. Ph.D. Dissertation, University of California, Berkeley, CA, US.

Fox, N.A. and Shonkoff, J.P. (2011). "How Persistent Fear and Anxiety Can Affect Young Children's Learning, Behavior and Health." Social and Economic Costs of Violence, National Academies Press, pp. 9-14.

Frese, M. and Keith, N. (2015). "Action Errors, Error Management, and Learning in Organizations." Ann. Rev. of Psychology, 66, pp. 661-687.

Goetsch, D.L. and Davis, S.B. (2014). Quality Management for Organizational Excellence: Introduction to Total Quality. Upper Saddle River, NJ: Pearson. 
Gomez, S., Huynh, R., Arroyo, P., Ballard, G., Tommelein, I., and Tillmann, P. (2019). "Changing Behaviors Upstream to Achieve Expected Outcomes." Proc. $27^{\text {th }}$ Ann. Conf. Int. Group for Lean Constr. Dublin, Ireland, pp. 13-24.

Gryna, F., Chua, R.C.H., and DeFeo, J.A. (2005). Juran's Quality Planning and Analysis for Enterprise Quality. Tata McGraw-Hill Education.

Howell, G., Ballard, G., and Demirkesen, S. (2017). "Why Lean Projects are Safer." Proc. $25^{\text {th }}$ Ann. Conf. Int. Group for Lean Constr., Heraklion, Greece, pp. 4-12.

Juran, J.M. (1995). A History of Managing for Quality: The Evolution, Trends, and Future Directions of Managing for Quality. Juran Foundation, Inc.

Juran, J.M. and Godfrey, A.B. (1999). Juran's Quality Handbook. $5^{\text {th }}$ ed., New York, McGraw-Hill.

Juran, J.M., and Gryna, F.M. (1988). Juran's Quality Control Handbook. $4^{\text {th }}$ ed., New York, McGraw-Hill.

Kahn, W.A. (1990). "Psychological Conditions of Personal Engagement and Disengagement at Work.” Academy of Management J., 33(4), 692-724.

Koskela, L., Tezel, A., and Patel, V. (2019). "Theory of Quality Management: Its Origins and History." Proc. $27^{\text {th }}$ Ann. Conf. Int. Group for Lean Constr., Dublin, Ireland, pp. 1381-1390.

Lean Construction Industry (LCI) (2020). Lean Construction Industry Glossary. https://www.leanconstruction.org/learning/education/glossary visited 11 June 2019.

Macomber, H. and Howell, G.A. (2003). "Linguistic Action: Contributing to the Theory of Lean Construction." Proc. $11^{\text {th }}$ Ann. Conf. Int. Group for Lean Constr., Virginia, USA, pp. 1-10.

Milliken, F.J., Morrison, E., and Hewlin, P. (2003). “An Exploratory Study of Employee Silence: Issues that Employees don't Communicate Upward and Why." J. of Management Studies, 40(6), 1453-1476.

Mills, A. (2001). "A Systematic Approach to Risk Management for Construction." Structural Survey, 19, 245-252.

Mitropoulos, P. and Memarian, B. (2012). "Team Processes and Safety of Workers: Cognitive, Affective, And Behavioral Processes of Construction Crews." J. of Constr., Engineering and Management, 138(10), 1181-1191.

Pounds, J., Werner, T., Moran, D., and Foxworthy, B. (2015). Quality, Behavior, and The Bottom Line: The Human Side of Quality Improvement. Createspace Pub., 128pp.

Ryan, K.D. and Oestreich, D. K. (1991). Driving Fear Out of the Workplace: How to Overcome the Invisible Barriers to Quality, Productivity, and Innovation. San Francisco: Jossey-Bass.

Schein, E.H. (1985). Organizational Culture and Leadership. San Francisco: Jossey-Bass. Schein, E.H. (1992). "How can Organizations Learn Faster? The Problem of Entering the Green Room." Sloan Management Review. 34(2), 85-92.

Spencley, R., Pfeffer, G., Gordon, E., Hain, F., Reed, D., and Marosszeky, M. (2018). "Behavior-Based Quality Closing the Knowing Doing Gap." Proc. $26^{\text {th }}$ Ann. Conf. Int. Group for Lean Constr., Chennai, India, pp. 1170-1181.

Tucker, A.L. and Edmondson, A.C. (2003). "Why Hospitals don't Learn from Failures: Organizational and Psychological Dynamics that Inhibit System Change." California Management Review, 45(2), 55-72.

Winograd, T. (1986). "A Language/Action Perspective on the Design of Cooperative Work." Proc. 1986 ACM Conf. Computer-Supported Cooperative Work, pp. 203-220. 